\title{
Transition Metal-free Epoxidation of Alkenes Based on the Existence of (2- hydroxypropyl)- $\beta-C D$
}

\author{
Shi Dongpo*, Yin Xianqing, Zheng Yancheng, Chen wu, Fu Jiaxin and Ren Zhaohua \\ Key Laboratory of Exploration Technologies for Oil and Gas Resources (Yangtze University), Jingzhou, Hubei, 434023, \\ P.R. China
}

\begin{abstract}
A green, efficient epoxidation of alkenes with hydrogen peroxide $\left(\mathrm{H}_{2} \mathrm{O}_{2}\right)$ and sodium bicarbonate $\left(\mathrm{NaHCO}_{3}\right)$ catalyzed by (2-hydroxypropyl)- $\beta$-cyclodextrin $(2-\mathrm{hp}-\beta-\mathrm{CD})$ in aqueous solution has been investigated in detail. A range of alkenes were epoxidized at ambient temperature with high yields.
\end{abstract}

Keywords: 2 -hp- $\beta$-cyclodextrin, alkenes, epoxidation, inclusion complex.

\section{INTRODUCTION}

It is significant for the epoxidation of alkenes because of the production of epoxides, a major industrial organic intermediate and is used as the critical raw materials of drugs, chemicals and food [1,2]. Lane and Burgess [3] reviewed metal-catalyzed epoxidations of alkenes with hydrogen peroxide, the loss of active metal ingredients and use of toxic organic solvents in some reactions made the process less satisfactory. Thus, metal-free epoxidation of alkenes under mild aqueous conditions with biocatalytic approaches [4-8] are attracting increasing interest, these enzyme catalysts are renewable, non-toxic and biodegradable. Moreover, metal-free asymmetric epoxidations [911] have also been developed recently. The increasing focus on the metal-free epoxidation of alkenes promotes further optimization of these methods toward greener processes.

Cyclodextrins, which wre cyclic oligosaccharides with hydrophobic cavities, can promote oxidation with excellent selectivity via non-covalent bonding of host-guest complexes [12] as seen in enzymes; and the corresponding reports [13-16] about epoxidation and organic synthesis catalyzed by $\mathrm{hp}-\beta$-cyclodextrin and its derivatives in water involving the formation of host-guest complexes are increasing. The inclusion rests with the space structures, size, and hydrogen bonds of the guest [17, 18]. It was ever reported that cyclodextrin derivatives could promote the asymmetric epoxidation of alkenes by working as catalyst or the host of the cyclodextrin-substrate complex [19-22]; Chan and coauthors [21] reported a ketoester form the modified cyclodextrin for asymmetric epoxidation of a series of alkenes in 31 40\% ee. Rousseau and coauthors [22] investigated four cyclodextrin derivatives as catalysts for space selective epoxidation of a series of alkenes in $0 \sim 45 \%$ ee with yield of 17 100\% in the existence of oxone.

*Address correspondence to this author at the key laboratory of exploration technologies for oil and gas resources (Yangtze University), Jingzhou, Hubei, 434023, P.R. China; Tel: 13797295601;

E-mail: shidongpo2006@126.com
In lots of research fields involving cyclodextrins, we focused on its substrate-selective reactions [23-25]. Surendra [26] reported a novel method about the oxidation of lots of alcohols with $\mathrm{NaClO}$ and $\mathrm{KBr}$ as oxidants, in comparison with their report, only these alcohols with suitable shape, size and space structures could be oxidized with high yields in our report [23]. It had been shown earlier that substrateselective oxidation of aldehydes [24] and sulfides [25] were achieved in the same way. In continuation of our efforts, a mild, transition metal-free and substrate-selective approach for the epoxidation of alkenes with $\mathrm{H}_{2} \mathrm{O}_{2} / \mathrm{NaHCO}_{3}$ catalyzed by 2 -hp- $\beta$-cyclodextrin in aqueous solution has been developed.

\section{EXPERIMENTAL}

The epoxidation was carried out as follows. $30 \mathrm{~mL}$ of double-distilled water was heated to $60^{\circ} \mathrm{C}, 2 \mathrm{mmol} 2$-hp- $\beta$ cyclodextrin could be completely dissolved in this water by stirring constantly for about 2 minutes. At this time, $2 \mathrm{mmol}$ styrene was slowly dropped into the solution. Then $25 \mathrm{mmol}$ sodium bicarbonate and $4 \times 1 \mathrm{~mL}$ of $30 \% \mathrm{H}_{2} \mathrm{O}_{2}$ was slowly added. The crude product was separated by adding ethyl acetate $(60 \mathrm{~mL})$, dried in a vacuum until the solvent was completely removed. Epoxides were all analyzed by GCMSQP2010.

\section{RESULTS AND DISCUSSION}

An efficient, selective and transition metal-free epoxidation of alkenes with $\mathrm{H}_{2} \mathrm{O}_{2} / \mathrm{NaHCO}_{3}$ as an oxidant catalyzed by 2 -hp- $\beta$-cyclodextrin was achieved here with water as the only solvent (Scheme 1).

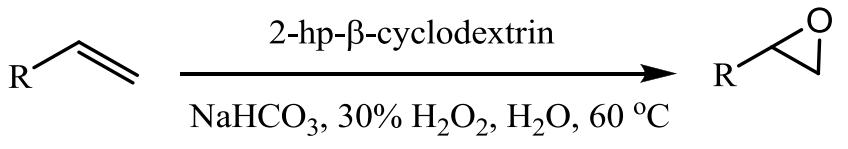

Scheme 1. Epxidation of alkenes catalyzed by (2-hp- $\beta-C D)$ in aqueous solution. 
In order to achieve the optimum epoxidation conditions, styrene as a representative reagent has been investigated at different temperatures; the results are shown in Fig. (1).

Fig. (1) shows that temperature could essentially affect the conversion of styrene and the yield and ratio of the oxidation products (2-phenyloxirane and benzaldehyde). While the reaction temperature was lower than $60^{\circ} \mathrm{C}$, the epoxidation rate increased with the increasing temperature, and styrene could be almost completely converted to 2phenyloxirane without side reactions (curves $\mathrm{a}, \mathrm{b}$ and $\mathrm{c}$ ); however, if the reaction temperature was over $60^{\circ} \mathrm{C}$, the yield of the desired product 2-phenyloxirane decreased with the increasing temperature, and the by-product such as benzaldehyde could be formed via oxidative cleavage of double bond (curve c). Moreover, elevated temperature promoted decomposition of hydrogen peroxide. Therefore, $60^{\circ} \mathrm{C}$ was used as the optimum temperature in the later experiments.

During the investigation of biomimetic approaches for styrene with hydrogen peroxide involving 2 -hp- $\beta$ cyclodextrin in water, it was found that the different amounts of 2-hp- $\beta$-cyclodextrin, hydrogen peroxide and sodium bicarbonate could influence the conversion of styrene and the yields of products dramatically, as shown in Table $\mathbf{1}$ and Table 2.

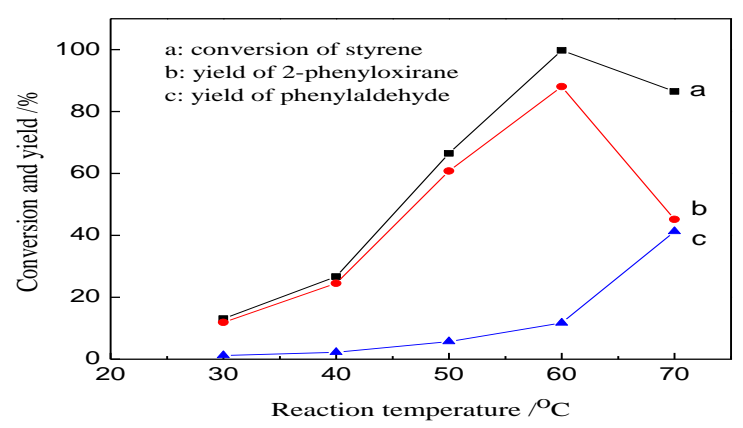

Fig. (1). Epoxidation of styrene under different temperatures.

Reaction conditions: 2-hp- $\beta$-cyclodextrin (2 mmol), styrene (2 mmol), $\mathrm{H}_{2} \mathrm{O}(30 \mathrm{~mL}), \mathrm{NaHCO}_{3}(25 \mathrm{mmol}), 4 \times 1 \mathrm{~mL}$ of $30 \% \mathrm{H}_{2} \mathrm{O}_{2}$ $(1 \mathrm{~mL}$ at the start, then $1 \mathrm{~mL}$ every $0.5 \mathrm{~h}$ ), reaction time $2.5 \mathrm{~h}$.

Table 1 (entries 1 4) shows the results of the effect of the amount of hydrogen peroxide and the mode of its addition (in 1 or 4 portions) on the product ratio. The conversion of styrene and the yield of 2-phenyloxirane increased with the increasing amount of hydrogen peroxide. When the hydrogen peroxide $(4 \mathrm{~mL})$ was added in 4 portions $(1 \mathrm{~mL}$ at the start, then $1 \mathrm{~mL}$ every $0.5 \mathrm{~h}$ ) at $60^{\circ} \mathrm{C}$, the conversion of styrene increased to $99 \%$ against $53 \%$ (addition at once,

Table 1. Effect of the different amounts of 2-hp- $\beta$-cyclodextrin and $\mathrm{H}_{2} \mathrm{O}_{2}$ on the epoxidation of styrene ${ }^{\mathrm{a}}$.

\begin{tabular}{|c|c|c|c|c|}
\hline Entry & Amount of hp- $\beta$-CD / mmol & $\begin{array}{c}\text { Amount of } \mathbf{3 0 \%} \mathbf{H}_{\mathbf{2}} \mathbf{O}_{2} / \\
\mathbf{m L}\end{array}$ & Conv. / \% & Yield of 2-phenyloxirane / \% \\
\hline \hline 1 & 2 & 0 & 0 & 34 \\
\hline 2 & 2 & 2 & 39 & 47 \\
\hline 3 & 2 & 4 & 79 & 88 \\
\hline 4 & 2 & $4^{\mathbf{b}}$ & 49 & 28 \\
\hline 5 & 0 & $4^{\mathbf{b}}$ & 78 & 51 \\
\hline 6 & 0.5 & $4^{\mathbf{b}}$ & 92 & 71 \\
\hline
\end{tabular}

${ }^{\mathrm{a}}$ Reaction conditions: styrene $(2 \mathrm{mmol}), \mathrm{H}_{2} \mathrm{O}(30 \mathrm{~mL}), \mathrm{NaHCO}_{3}(25 \mathrm{mmol}), 60^{\circ} \mathrm{C}$, reaction time $2.5 \mathrm{~h}$.

${ }^{\mathrm{b}} 1 \mathrm{~mL}$ at the start, then $1 \mathrm{~mL}$ every $0.5 \mathrm{~h}$.

Table 2. Epoxidation of styrene under the different amount of $\mathrm{NaHCO}_{3}{ }^{\text {a }}$.

\begin{tabular}{|c|c|c|c|}
\hline Entry & Amount of $\mathbf{N a H C O}_{\mathbf{3}}$ / mmol & Conv. / \% & Yield of 2-phenyloxirane / \% \\
\hline \hline 1 & 0 & 0 & 0 \\
\hline 2 & 15 & 87 & 59 \\
\hline 3 & 25 & $>99$ & 88 \\
\hline 4 & 35 & 82 & 65 \\
\hline
\end{tabular}

${ }^{a}$ Reaction conditions: 2-hp- $\beta$-cyclodextrin $(2 \mathrm{mmol})$, styrene $(2 \mathrm{mmol}), \mathrm{H}_{2} \mathrm{O}(30 \mathrm{~mL}), 4 \mathrm{~mL}$ of $30 \% \mathrm{H}_{2} \mathrm{O}_{2}(1 \mathrm{~mL}$ at the start, then $1 \mathrm{~mL}$ every $0.5 \mathrm{~h}), 60^{\circ} \mathrm{C}$, reaction time $2.5 \mathrm{~h}$. 
entry 3), and the the yield of the desired product 2phenyloxirane increased from $47 \%$ to $88 \%$. It should be also noticed the amount of 2 -hp- $\beta$-cyclodextrin was sensitive. When the amount of 2 -hp- $\beta$-cyclodextrin was less than 2 mmol, 2 mmol styrene could not be completely oxidized at $60^{\circ} \mathrm{C}$, and the yield of 2-phenyloxirane was also much lower (entries 5-7).

Sodium bicarbonate was used to produce peroxy acids instantly from hydrogen peroxide in the classical bicarbonate-activated peroxide route $[27,28]$. The peroxy acid generated was then utilised directly for the epoxidation of styrene. Table 2 (entries 1 4) shows that $\mathrm{NaHCO}_{3}$ additive is crucial and styrene could not be oxidized at all without sodium bicarbonate (entry 1). The amount of sodium bicarbonate affected the oxidation greatly, rise in the amount of sodium bicarbonate strongly increased the conversion of styrene $(2 \mathrm{mmol}$ ) from 0 to $99 \%$ and the yield of 2phenyloxirane from 0 to $88 \%$ (entries 1 and 3). However, when the amount of sodium bicarbonate was higher than 25 mmol, both the conversion of styrene and the yield of 2phenyloxirane were significantly reduced (entry 4).

Therefore, $2 \mathrm{mmol}$ of 2 -hp- $\beta$-cyclodextrin, $4 \mathrm{~mL}$ of $30 \%$ $\mathrm{H}_{2} \mathrm{O}_{2}(1 \mathrm{~mL}$ at the start, then $1 \mathrm{~mL}$ every $0.5 \mathrm{~h}), 25 \mathrm{mmol}$ sodium bicarbonate and $60^{\circ} \mathrm{C}$ were determined as the optimum reaction condition for epoxidation of alkenes ( 2 mmol).

For the further application of the method, the epoxidation of several alkenes has been investigated under the above experimental conditions. The results of the epoxidation of these alkenes are shown as in Table $\mathbf{3}$.

It is well-known that cyclodextrins and substrates may form inclusion complex in aqueous solution [14, 15]. The inclusion rests with the space structures, size, and hydrogen bonds between cyclodextrin and guest. This interaction may activate the substrate and enhance the solubility of the substrate in aqueous solution [24]. In the present research, the space configuration of guest molecules is crucial for

Table 3. Epoxidation of various alkenes by $\mathrm{H}_{2} \mathrm{O}_{2}$ in the presence of 2-hp- $\beta$-cyclodextrin ${ }^{\mathrm{a}}$.

\begin{tabular}{|c|c|c|c|c|c|}
\hline Entry & Substrate & Product & Time/h & Conv. $/ \%$ & Yield $/ \%$ \\
\hline 1 & & & 2.5 & $>99$ & 88 \\
\hline 2 & & & 6 & $>99$ & 86 \\
\hline 3 & & & 2.5 & $>99$ & 92 \\
\hline 4 & & & 3.0 & $>99$ & 90 \\
\hline 5 & & & 6 & $>99$ & 90 \\
\hline 6 & & & 10 & 0 & 0 \\
\hline 7 & & & 10 & 0 & 0 \\
\hline 8 & & & 6 & 0 & 0 \\
\hline 9 & & & 6 & 0 & 0 \\
\hline
\end{tabular}

${ }^{a}$ Reaction conditions: substrate $(2 \mathrm{mmol}), 2$-hp- $\beta$-cyclodextrin $(2 \mathrm{mmol}), \mathrm{H}_{2} \mathrm{O}(30 \mathrm{~mL}), \mathrm{NaHCO}_{3}(25 \mathrm{mmol}), 4 \mathrm{~mL}$ of $30 \% \mathrm{H}_{2} \mathrm{O}_{2}(1 \mathrm{~mL}$ at the start, then $1 \mathrm{~mL}$ every $0.5 \mathrm{~h}), 60^{\circ} \mathrm{C}$. 


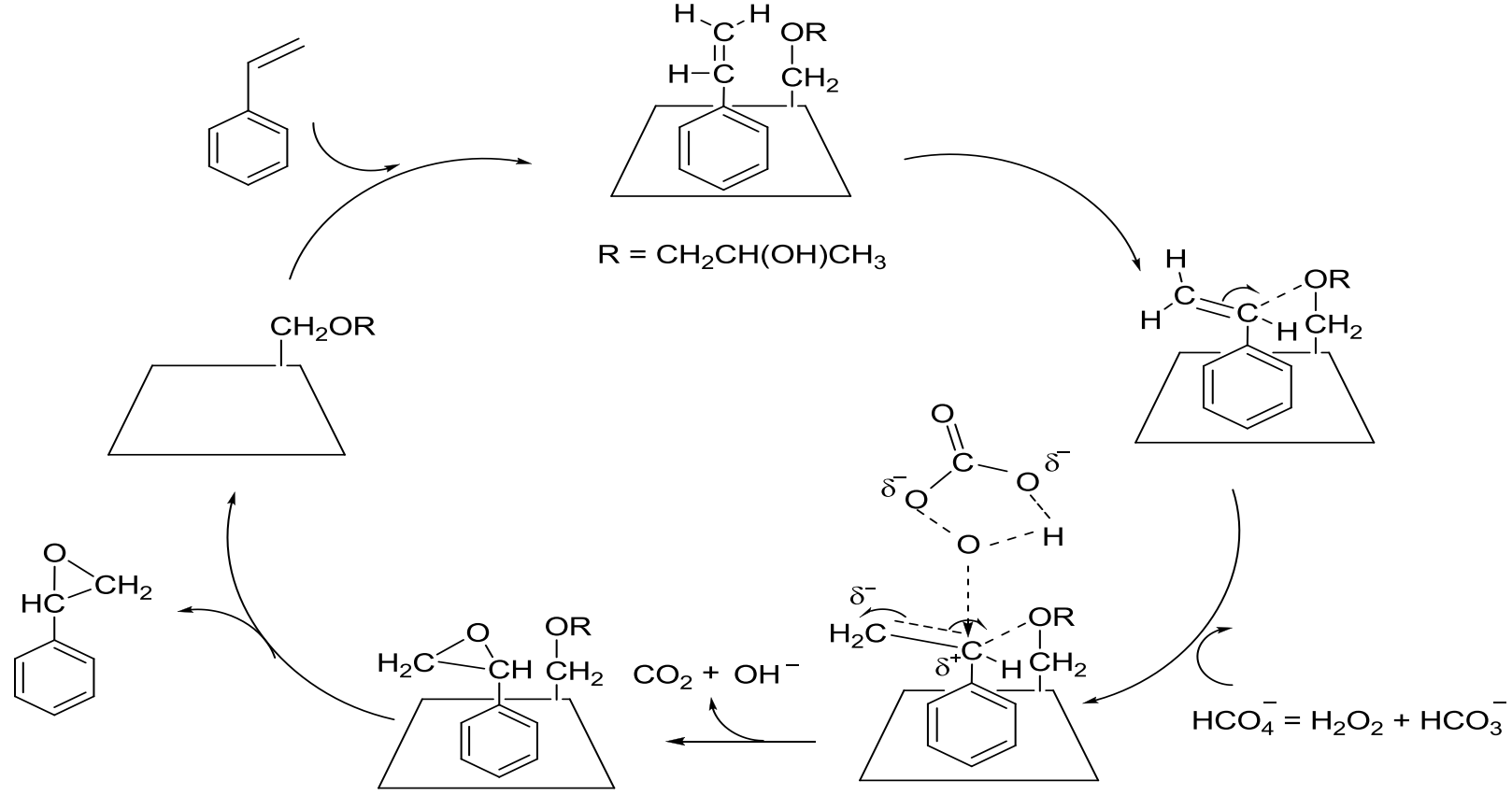

Fig. (2). Possible mechanism of the epoxidation of styrene in aqueous solution with the existence of 2-hp-b-cyclodextrin.

smooth epoxidation. As shown in Table 2, some aromatic alkenes (entries 1 2) and cyclohexenes (entries 3 5) could be oxidized to the corresponding epoxides catalyzed by 2 hp- $\beta$-cyclodextrin in water with excellent yields, however, some other aromatic alkenes or cyclohexenes (entries 6 7) could not be oxidized to the corresponding epoxides in the same reaction conditions, indicating that the epoxidation of alkenes was a substrate-selective reaction in the existence of 2 -hp- $\beta$-cyclodextrin in aqueous solution, and those alkenes with larger molecular size were hardly oxidized by hydrogen peroxide because the complexation of the alkenes and 2-hp$\beta$-cyclodextrin were hardly formed due to the larger steric effect (entries 6 7). This could be further supported by the fact that reaction rate of the epoxidation of D-limonene (entry 5) was much lower than cyclohexene (entry 3) or 1methylcyclohex-1-ene (entry 4) for the existence of $\left(\mathrm{CH}_{3} \mathrm{CH}=\mathrm{CH}_{2}\right)$ group.

1-octene and 2-octene could not be oxidized by $\mathrm{H}_{2} \mathrm{O}_{2}$ / $\mathrm{NaHCO}_{3}$ in 2-hp- $\beta$-cyclodextrin aqueous solution, no products were detected within 6 hours (entries 8 9). The result is similar to oxidation of 2-octanol and 1-octanol [23] or the reaction of 2-heptyl-1, 3-dioxolane [29] in water, where the inclusion composed of substrate with long chain alkyl groups and $\beta$-cyclodextrin were difficultly formed, the epoxidation of 1-octene and 2-octene was also hardly achieved.

Based on the above research, it could be concluded that the formation of the complexation of alkenes and 2-hp- $\beta$ cyclodextrin was crucial to the epoxidation of the alkenes in water. The oxidation might follow the pathway in Fig. (2). Firstly, 2-hp- $\beta$-cyclodextrin and styrene could form hostguest inclusion in aqueous solution. At this time, the anion $\mathrm{HCO}^{4-}$ produced from hydrogen peroxide attacked the styrene in water. Since the $\mathrm{C}=\mathrm{C}$ bond of styrene was weakened because of the existence of the 2-hp- $\beta$ cyclodextrin, the conversion of styrene would be accelerated.

\section{CONCLUSION}

In conclusion, a green, efficient, selective and biomimetic epoxidation of alkenes with $\mathrm{H}_{2} \mathrm{O}_{2} / \mathrm{NaHCO}_{3}$ as oxidant in water has been developed. The 2-hp- $\beta$ cyclodextrin could be easily recycled by adding some organic solvents like acetone, methanol and ethyl acetate [23].

\section{CONFLICT OF INTEREST}

The authors confirm that this article content has no conflict of interest.

\section{ACKNOWLEDGEMENTS}

We thank the National Natural Science Foundation of China (No.41202111) for financial support of this study.

\section{REFERENCES}

[1] T. Chattopadhyay, and D. Das, "Studies of the catalytic activity of $\mathrm{Fe}(\mathrm{III})($ salen) complexes as epoxidation catalysts", Journal of Coordination Chemistry, vol. 62, pp. 845-853, 2009.

[2] R. Hajian, S. Tangestaninejad, M. Moghadam, V. Mirkhani, I Mohammadpoor-Baltork, and A. R. Khosropour, "Olefin epoxidation with tert-BuOOH catalyzed by vanadium polyoxometalate immobilized on ionic liquid-modified MCM-41", Journal of Coordination Chemistry, vol. 64, pp. 4134-4144, 2011.

[3] B. S. Lane, and K. Burgess, "Metal-catalyzed epoxidations of alkenes with hydrogen peroxide", Chemical Reviews, vol. 103, pp. 2457-2473, 2003.

[4] N. O. Mahmoodi, M. R. Yazdanbakhsh, and F. Ghanbari, "Epoxidation of 1, 4-Diaroyl ethene derivatives in the presence of UHP or $\mathrm{H}_{2} \mathrm{O}_{2}$ ", Synthetic Communications, vol. 40, pp. 3181-3185, 2010.

[5] S. Cheung, V. McCarl, A. Holmes, N. Coleman, and P. Rutledge, "Substrate range and enantioselectivity of epoxidation reactions mediated by the ethene-oxidising Mycobacterium strain NBB4", Applied Microbiology \& Biotechnology, vol. 97, pp. 1131-1140, 2013.

[6] L. C. Nolan, and K. E. O'Connor, "Dioxygenase- and monooxygenasecatalysed synthesis of cis-dihydrodiols, catechols, 
epoxides and other oxygenated products", Biotechnology Letters, vol. 30 , pp. $1879-1891,2008$.

[7] E. Notomista, V. Cafaro, G. Bozza, and A. D. Donato, "Molecular determinants of the regioselectivity of toluene/o-xylene monooxygenase from Pseudomonas sp strain OX1", Applied and Environmental Microbiology, vol. 75, pp. 823-836, 2009.

[8] C. R. Owens, J. K. Karceski, and T. E. Mattes, "Gaseous alkene biotransformation and enantioselective epoxyalkane formation by Nocardioides sp strain JS614", Applied Microbiology and Biotechnology, vol. 84, pp. 685-692, 2009.

[9] M. T. Reetz, "Directed evolution of enantioselective enzymes: an unconventional approach to asymmetric catalysis in organic chemistry", Journal of Organic Chemistry, vol. 74, pp. 5767-5778, 2009.

[10] Y. Shi, "Organocatalytic asymmetric epoxidation of olefins by chiral ketones", Accounts of Chemical Research, vol. 37, pp. 488496, 2004

[11] O. Bortolini, G. Fantin, M. Fogagnolo, and L. Mari, "Control of the enantioselectivity by keto bile acid derivatives in the epoxidation of alkenes with Oxone", Tetrahedron-Asymmetry, vol. 15, pp. 38313833, 2004

[12] M. Raynal, P. Ballester, A. Vidal-Ferran, and P. W. van Leeuwen, "Supramolecular catalysis. Part 2: artificial enzyme mimics", Chemical Society Reviews, vol. 43, pp. 1734-1787, 2014.

[13] M. Fukudome, A. Matsushima, D. Q. Yuan, and K. Fujita, "Heterobifunctionalization of the secondary face of $\beta$-cyclodextrin: selective 3G-sulfonylation and subsequent $2 \mathrm{G}, 3 \mathrm{G}$-epoxidation of 3A-azido-3A-deoxy-altro- $\beta$-cyclodextrin", Tetrahedron Letters, vol. 47, pp. 6599-6602, 2006.

[14] S. S. Braga, S. Gago, J. D. Seixas, A. A. Valente, M. Pillinger, T. M. Santos, I. S. Gonçalves, and C. C. Romão, " $\beta$-Cyclodextrin and permethylated $\beta$-cyclodextrin inclusion compounds of a cyclopentadienyl molybdenum tricarbonyl complex and their use as cyclooctene epoxidation catalyst precursors", Inorganica Chimica Acta, vol. 359, pp. 4757-4764, 2006.

[15] A. C. Gomes, S. M. Bruno, C. Tomé, A. V. Anabela, M. Pillinger, M. Abrantes, and I. S. Gonçalves, "Synthesis and characterization of $\mathrm{CpMo}(\mathrm{CO}) 3(\mathrm{CH} 2-\mathrm{pC} 6 \mathrm{H} 4-\mathrm{CO} 2 \mathrm{CH} 3)$ and its inclusion compounds with methylated cyclodextrins. Applications in olefin epoxidation catalysis", Journal of Organometallic Chemistry, vol. 730, pp. 116-122, 2013

[16] J. Fischer, S. Millan, and H. Ritter, "N, N-(Hexane-1, 6-diyl)bis (4methyl-N-(oxiran-2-ylmethyl) benzenesulfonamide): Synthesis via cyclodextrin mediated $\mathrm{N}$-alkylation in aqueous solution and further Prilezhaevepoxidation", Beilstein Journal of Organic Chemistry, vol. 9, pp. 2834-2840, 2013.

[17] L. Khalafi, M. Rafiee, and S. Fathi, "Effect of $\beta$-cyclodextrin on intra and intermolecular Michael addition of some catechol derivatives", Spectrochimica Acta Part A-Molecular and Biomolecular Spectroscopy, vol. 118, pp. 695-701, 2014.
[18] M. Jouffroy, D. Armspach, A. Louati, D. Matt, and L. Toupet, "Capping methodology in cyclodextrin chemistry: use of a symmetrical diketone reagent for regiospecific installation of unsymmetrical imine-enamine and imidazole caps", Chemistry-A European Journal, vol. 20, pp. 2565-2573, 2014.

[19] K. M. Weiss, and S. B. Tsogoeva, "Enantioselective epoxidation of electron-deficient olefins: an organocatalytic approach", Chemical Record, vol. 11, pp. 18-39, 2011.

[20] L. Marinescu, M. Mølbach, C. Rousseau, and M. Bols, "Supramolecular oxidation of anilines using hydrogen peroxide as stoichiometric oxidant", Journal of the American Chemical Society, vol. 127, pp. 17578-17579, 2005.

[21] W. K. Chan, W. Y. Yu, C. M. Che, and M. K. Wong, "A cyclodextrin-modified ketoester for stereo-selective epoxidation of alkenes", Journal of Organic Chemistry, vol. 68, pp. 6576-6582, 2003.

[22] C. Rousseau, B. Christensen, and M. Bols, "Artificial Epoxidase II. Synthesis of Cyclodextrin Ketoesters and Epoxidation of Alkenes", European Journal of Organic Chemistry, vol. 2005, pp. 2734-2739, 2005 .

[23] H. B. Ji, D. P. Shi, M. Shao, Z. Li, and L. F. Wang, "Transition metal-free and substrate-selective oxidation of alcohols using water as an only solvent in the presence of $\beta$-cyclodextrin", Tetrahedron Letters, vol. 46, pp. 2517-2520, 2005.

[24] D. P. Shi, and H. B. Ji, " $\beta$-Cyclodextrin promoted oxidation of aldehydes to carboxylic acids in water", Chinese Chemical Letters, vol. 20, pp. 139-142, 2009.

[25] H. B. Ji, X. F. Hu, D. P. Shi, and Z. Li, "Controllable oxidation of sulfides to sulfoxides and sulfones with aqueous hydrogen peroxide in the presence of $\beta$-cyclodextrin", Russian Journal of Organic Chemistry, vol. 42, pp. 959-961, 2006.

[26] K. Surendra, N. S. Krishnaveni, and K. R. Rao, "A simple biomimetic protocol for the oxidation of alcohols with sodium hypochlorite in the presence of $\beta$-cyclodextrin in water", Canadian Journal of Chemistry, vol. 82, pp. 1230-1233, 2004.

[27] G. Chatel, C. Goux-Henry, N. Kardos, J. Suptil, B. Andrioletti, and M. Draye, "Ultrasound and ionic liquid: An efficient combination to tune the mechanism of alkenes epoxidation", Ultrasonics Sonochemistry, vol. 19, pp. 390-394, 2012.

[28] E. Abdulmalek, M. Arumugam, R. M. B. Abdul, M. Basri, and A. B. Salleh, "Enzyme-facilitated synthesis of 1-nonene oxide and simple GC-MS SIM method for rapid screening of epoxidation processes", Biocatalysis \& Biotransformation, vol. 30, pp. 476484, 2012.

[29] H. B. Ji, "Highly shape-selective,biomimetic, and efficient deprotection of carbonyl compounds masked as ethylene acetals or dioxolanes produced from 1,2-ethanediol", European Journal of Organic Chemistry, vol. 2003, pp. 3659-3662, 2003.

(C) Dongpo et al.; Licensee Bentham Open.

This is an open access article licensed under the terms of the Creative Commons Attribution Non-Commercial License (http://creativecommons.org/licenses/by-nc/3.0/) which permits unrestricted, non-commercial use, distribution and reproduction in any medium, provided the work is properly cited. 